\title{
RESEARCH
}

Open Access

\section{Explaining income-related inequalities in cardiovascular risk factors in Tunisian adults during the last decade: comparison of sensitivity analysis of logistic regression and Wagstaff decomposition analysis}

\author{
Olfa Saidi ${ }^{1,2^{*}}$ (D), Nada Zoghlami ${ }^{1,2}$, Kathleen E. Bennett ${ }^{3}$, Paola Andrea Mosquera ${ }^{4}$, Dhafer Malouche ${ }^{1,5}$,
} Simon Capewe $\|^{6}{ }^{6}$ Habiba Ben Romdhane ${ }^{1}$ and Martin O'Flaherty ${ }^{6}$

\begin{abstract}
Background: It is important to quantify inequality, explain the contribution of underlying social determinants and to provide evidence to guide health policy. The aim of the study is to explain the income-related inequalities in cardiovascular risk factors in the last decade among Tunisian adults aged between 35 and 70 years old.

Methods: We performed the analysis by applying two approaches and compared the results provided by the two methods. The methods were global sensitivity analysis (GSA) using logistic regression models and the Wagstaff decomposition analysis.

Results: Results provided by the two methods found a higher risk of cardiovascular diseases and diabetes in those with high socio-economic status in 2005. Similar results were observed in 2016.

In 2016, the GSA showed that education level occupied the first place on the explanatory list of factors explaining $36.1 \%$ of the adult social inequality in high cardiovascular risk, followed by the area of residence (26.2\%) and income (15.1\%). Based on the Wagstaff decomposition analysis, the area of residence occupied the first place and explained $40.3 \%$ followed by income and education level explaining 19.2 and $14.0 \%$ respectively. Thus, both methods found similar factors explaining inequalities (income, educational level and regional conditions) but with different rankings of importance.
\end{abstract}

Conclusions: The present study showed substantial income-related inequalities in cardiovascular risk factors and diabetes in Tunisia and provided explanations for this. Results based on two different methods similarly showed that structural disparities on income, educational level and regional conditions should be addressed in order to reduce inequalities.

Keywords: Social inequalities, Global sensitivity analysis (GSA), Logistic regression, Wagstaff-type decomposition analysis, Diabetes, Cardiovascular risk factors, Tunisia

* Correspondence: olfa.saidi@yahoo.fr

${ }^{1}$ Cardiovascular Epidemiology and Prevention Research Laboratory -Faculty

of medicine of Tunis, University Tunis El Manar, Tunis, Tunisia

${ }^{2}$ National Institute of Health, Tunis, Tunisia

Full list of author information is available at the end of the article

(c) The Author(s). 2019 Open Access This article is distributed under the terms of the Creative Commons Attribution 4.0 International License (http://creativecommons.org/licenses/by/4.0/), which permits unrestricted use, distribution, and reproduction in any medium, provided you give appropriate credit to the original author(s) and the source, provide a link to the Creative Commons license, and indicate if changes were made. The Creative Commons Public Domain Dedication waiver (http://creativecommons.org/publicdomain/zero/1.0/) applies to the data made available in this article, unless otherwise stated. 


\section{Key messages}

- Our study explains the income-related inequalities in cardiovascular risk factors among Tunisian adults during the last decade.

- It compares two methods (sensitivity analysis of logistic regression model and Wagstaff decomposition analysis).

- Both methods pointed tofound similar factors explaineding inequalities (income, educational level and regional conditions (area and region)) but with different rankings of importance.

\section{Introduction}

Inequalities in health are considered unacceptable as Alma-Ata declared in 1978 by stating that "the existing gross inequality in the health status of the people particularly between developed and developing countries as well as within countries is politically, socially and economically unacceptable and is, therefore, of common concern to all countries" [1]. Accordingly, the World Health Organization (WHO) has issued a call to action to reduce health inequalities [2].

Several epidemiological studies have examined the income-related inequalities of noncommunicable diseases, in particular cardiovascular diseases (CVDs) and diabetes. Cardiovascular risk factors are well documented in Tunisia [3, 4]. However, such studies have been unable to address policy makers concerns on which interventions and preventive strategies will be most effective in reducing the observed inequalities and how to address the groups most in need of intervention $[5,6]$.

The major limitation of Tunisian and international research on income-related inequalities of cardiovascular diseases and diabetes is the dominant focus on the existence of inequalities without identifying their basis, which would allow greater understanding of the reasons for inequalities [7-10]. Some advanced statistical methods can help overcome many of these limitations playing a crucial role in helping to quantify inequality and explain the contribution of the underlying social determinants as well as to guide health policies and the development of strategies at different levels $[11,12]$.

In this context, this study aimed to quantify the income-related inequalities in five cardiovascular risk factors (diabetes, hypertension, obesity, hypercholesterolemia, smoking and high cardiovascular risk) in the last decade in Tunisia, and to determine the contribution of a broad range of social determinants of the inequalities. In order to identify the most explanatory social determinants, we used the two main approaches currently used to explain social inequalities, a global sensitivity analysis using logistic regression model and the Wagstaff-type decomposition analysis.

\section{Methods}

\section{Study population}

To study the evolution of income-related inequalities of cardiovascular risk factors in Tunisia during the last decade, we used two large national surveys: (i) the Epidemiological Transition and Health Impact in North Africa Survey in 2005 (TAHINA-2005) including 8007 individuals aged 35-70 years old (3417 men and 4590 women) and (ii) the Tunisian Health Examination Survey (THES-2016) in 2016 including 6007 individuals aged $35-70$ years old ( 2859 men and 3148 women).

The two surveys used were representative of the underlying population and were based on the same sampling method. The definitions of cardiovascular risk were the same except for diabetes in 2016 where the Hemoglobin A1C was integrated as recommended by the American Diabetes Association.

Details of the study population were presented in the technical appendix.

\section{Measurements \\ Socio-economic and demographic variables}

The variables used as social determinants in our study included demographic and socio-economic factors that had plausible links with cardiovascular risk factors and diabetes [13, 14].

Demographic factors included four variables: (i) gender defined as male coded " 1 " and female coded "2"; (ii) age categorized into four groups: "1" 35-44, "2" 44-54, " 3 " 55-64 and "4" 65-70 years; (iii) geographic area ("1" Urban, "2" Rural) and (iv) region of residence categorized into7 administrative regions of the country ("1" District of Tunis, "2" North-East, "3" North-West, "4" Central-East, "5" Central-West, "6" South-East and South-West).

Data on geographic area and region of residence was obtained from the sampling frame derived by the Tunisian National Institute of Statistics $[15,16]$. Age and gender were self-reported by the survey participants.

Socio-economic factors included level of education, professional occupation and quintile of well-being. Data were self-reported by the survey participants.

(i) Education was classified according to the classification of National Tunisian Institute of Statistics into four categories [17]: level 0, Never educated "illiterate"; level 1, low level education "Primary" (6 years of schooling); level 2, intermediate-level education "Secondary" (7-13 years of schooling) and level 3 , higher education "university and higher ( $>=14$ years of schooling).

(ii) The classification of the professional activity status is defined according to the structure of the International Standard Classification of Occupations 
[18] and categorized into four groups: 1 higher level Senior level; 2 Intermediate level; 3 workers and 4 unemployed or retirees.

(iii) Quintile of income: income of household as categorized into quintiles with quintile 1 representing the lowest income and quintile 5 representing the highest.

\section{Cardiovascular risk factors}

Hypertension In both surveys (TAHINA-2005 and THES-2016), three blood pressure readings were measured separately; the mean systolic blood pressure (SBP) and diastolic blood pressure (DBP) of the three measures were considered. Based on WHO recommendations the following is considered hypertensive; any person with a $\mathrm{SBP}>=140$ and / or $\mathrm{DBP}>=90 \mathrm{mmHg}$ and / or who claims to be diagnosed for arterial hypertension and / or treated [19].

Diabetes For TAHINA Survey in 2005, diabetes prevalence was defined using the WHO criteria [20] as Fasting Plasma Glucose (FPG) $\geq 7 \mathrm{mmol} / \mathrm{L}$, confirmed medication usage from the medication inventory, selfreported use of antidiabetic medications within the past 2 weeks of the examination, or self-reported diabetes diagnosis.

For THES Survey in 2016, diabetes prevalence was defined according to the definition of the American Diabetes Association (ADA) as $\mathrm{FPG}>=7 \mathrm{mmol} / \mathrm{L}$ or postprandial glucose $>=11 \mathrm{mmol} / \mathrm{L}$, Hemoglobin A1C $(\mathrm{HbA} 1 \mathrm{C})>=6.5 \%$, self-reported diabetes diagnosis or confirmed medication usage from the medication inventory $[21,22]$.

Hypercholesterolemia In both surveys (TAHINA-2005 and THES-2016), the prevalence of hypercholesterolemia is defined by total serum cholesterol $\geq 6.2 \mathrm{mmol} / 1$ or triglyceride $\geq 3 \mathrm{mmol} /$ or self-reported hypercholesterolemia diagnosis [23].

Obesity In both surveys (TAHINA-2005 and THES2016), obesity is defined by Body Mass Index (BMI) $>=$ $30 \mathrm{Kg} / \mathrm{m}^{2}$ [24].

Smoking In both surveys (TAHINA-2005 and THES2016), the prevalence of smoking is defined by the daily consumption of tobacco at the time of the survey.

High cardiovascular risk In both surveys (TAHINA2005 and THES-2016), high cardiovascular risk is defined by the cumulative number of risk factors $\geq 3$, out of the five mentioned above.
In the main manuscript, we only present results of the high cardiovascular risk. The analysis of other individual factors (Diabetes, Tobacco, obesity, hypertension and hypercholesterolemia) are presented in the technical appendix.

\section{Statistical analysis \\ Sensitivity analysis to select the most influencing risk factors}

The Global Sensitivity Analysis (GSA) was defined as how the uncertainty in the output of a model can be apportioned to the different sources of uncertainty in the model input. The method quantifies the contribution of uncertainty in different social determinants (inputs) to a specific output variable of interest (the disease) $[25,26]$.

The GSA in this study is generally based on the sensitivity index for measuring the importance of a given social determinant on the output variable designating the disease (sick, not sick, eg hypertension).

The sensitivity index of a determinant is defined by the fractional contribution to the variance of the output variable.

\section{GSA in a logistic regression model}

In this study, we are interested in the sensitivity analysis of the logistic regression model.

The theory of constructing a logistic regression model is detailed in the appendix $[27,28]$.

The process of selecting the important covariates from the available set of covariates and constructing an appropriate logistic regression model involved three steps:

1) To identify the probability distribution $f\left(x_{i}\right)$ of each covariate in the model.

2) The logistic regression model, in terms of Logit (as in equation below) and the information about the covariates obtained in step one are used to create a Monte Carlo simulation to generate the sample that will be used in the decomposition and to estimate the unconditional variance of the response probability and the conditional variance for covariates.

3) The results from step two will be used in performing GSA in the binary logistic regression model and in the decomposition analysis, resulting in the estimate of $\mathrm{S}_{\mathrm{i}}$. In this step, we refer to the Sabol method [28] using R software.

\section{Wagstaff-type decomposition analysis}

The decomposition analysis quantifies the degree of income-related inequalities and explains the contribution of each factor to the observed inequality. The decomposition approach is the analysis of the contribution 
that each of the inequalities in the social determinants has on the inequalities in the observed disease.

This analysis is based on the concentration curve (CC) and the concentration index $(C)$ [29].

The analysis was done through the following steps:

1) Run a regression analysis;

2) Compute the elasticity (weighted coefficient);

3) Calculate the concentration indexes of the covariates;

4) Calculate the contributions.

Details of the method were presented in the technical appendix.

\section{Results}

Socioeconomic and demographic characteristics of the study populations

Table 1 shows the socioeconomic and demographic characteristics of the study populations.

In 2005, the mean age of the study population was $49.0 \pm 9.5$ years. Women accounted $50.4 \%$ of the study population and $68.0 \%$ lived in an urban area of residence. About one in four people were residing in the District of Tunis. $34.9 \%$ were illiterate, as well $43.2 \%$ were unemployed or retired. Additionally, $15.7 \%$ of the surveyed population lived at the lowest quintile in 2005.

In 2016, the mean age was $49.2 \pm 9.7$ years, and women accounted for $50.2 \%$ of the study population. The percentage of urban population was $67.6 \%$. In addition, $23.2 \%$ of the study population were residents in the District of Tunis region and $19.3 \%$ reported having no education in 2016. In addition, 39.9\% were unemployed or retired. The percentage of the surveyed population lived at the lowest quintile was $18.1 \%$.

\section{High cardiovascular risk in the last decade by social determinants \\ Evolution of high cardiovascular risk prevalence in the last decade by social determinants}

Table 2 presented the high cardiovascular risk prevalence by social determinants in 2005 and 2016. In 2005, $12.4 \%$ [11.4-13.3] of the adults aged 35-70 years old had high cardiovascular risk (13.6\% [12.0-15.0] among men and $11.2 \%$ [10.1-12.4] among women).

A greater prevalence of high cardiovascular risk was observed in those aged 55-64 years of age (19.1\% [16.5-21.7]) compared to those aged between 35 and 44 years $(7.4 \%$ [6.2-8.7]). High cardiovascular risk was twice as high in the urban area (14.8\% [13.5-16.1]) compared to the rural area (7.3\% [6.3-8.3]) and three times higher in the District of Tunis (19.2\% [16.3-22.0]) than in the north-west (6.6\% [5.28.1]). The High cardiovascular risk prevalence was more dominant among people with secondary education level
Table 1 Socioeconomic and demographic characteristics of the population studies in 2005 and 2016

\begin{tabular}{|c|c|c|c|c|}
\hline \multirow[t]{2}{*}{ Study } & \multicolumn{2}{|c|}{$\begin{array}{l}\text { TAHINA-2005 } \\
N=7553\end{array}$} & \multicolumn{2}{|c|}{$\begin{array}{l}\text { THES-2016 } \\
N=5449\end{array}$} \\
\hline & $\mathrm{N}$ & Weighted \% & $\mathrm{N}$ & Weighted \% \\
\hline \multicolumn{5}{|l|}{ Characteristics } \\
\hline \multicolumn{5}{|l|}{ Gender } \\
\hline Male & 3233 & 49.6 & 2610 & 49.8 \\
\hline Female & 4320 & 50.4 & 2839 & 50.2 \\
\hline \multicolumn{5}{|l|}{ Age-Groups (years) } \\
\hline $35-44$ & 2992 & 43.2 & 1803 & 37.5 \\
\hline $45-54$ & 2469 & 31.0 & 1708 & 31.5 \\
\hline $55-64$ & 1319 & 17.2 & 1443 & 23.4 \\
\hline $65-70$ & 773 & 8.5 & 495 & 7.6 \\
\hline Mean age & \multicolumn{2}{|c|}{$49.0 \pm 9.5$} & \multicolumn{2}{|c|}{$49.2 \pm 9.7$} \\
\hline \multicolumn{5}{|l|}{ Area } \\
\hline Urban & 4372 & 67.7 & 3606 & 67.6 \\
\hline Rural & 3181 & 32.3 & 1843 & 32.4 \\
\hline \multicolumn{5}{|l|}{ Region } \\
\hline District of Tunis & 925 & 24.4 & 685 & 23.2 \\
\hline North East & 1024 & 14.0 & 799 & 15.0 \\
\hline North West & 1124 & 13.0 & 886 & 11.8 \\
\hline Centre East & 1099 & 22.4 & 836 & 24.6 \\
\hline Centre West & 1176 & 12.3 & 763 & 11.9 \\
\hline South East & 1070 & 8.4 & 708 & 8.0 \\
\hline South West & 1135 & 5.5 & 772 & 5.5 \\
\hline \multicolumn{5}{|l|}{ Level of education } \\
\hline Illiterate & 3258 & 34.9 & 1240 & 19.3 \\
\hline Primary & 2588 & 35.1 & 2117 & 39.2 \\
\hline Secondary & 1233 & 20.1 & 1472 & 28.9 \\
\hline University & 474 & 9.8 & 620 & 12.6 \\
\hline \multicolumn{5}{|l|}{ Occupation } \\
\hline Upper & 980 & 15.8 & 484 & 10 \\
\hline Intermediate & 359 & 6.0 & 317 & 6.8 \\
\hline Employee/worker & 2370 & 35.0 & 2187 & 43.4 \\
\hline Unemployed/retired & 3844 & 43.2 & 2461 & 39.9 \\
\hline \multicolumn{5}{|l|}{ Household income } \\
\hline 1st quintile & 1510 & 15.7 & 1089 & 18.1 \\
\hline 2nd quintile & 1510 & 17.3 & 1090 & 19.0 \\
\hline 3rd quintile & 1511 & 20.6 & 1090 & 20.9 \\
\hline 4th quintile & 1511 & 21.0 & 1090 & 21.5 \\
\hline 5th quintile & 1511 & 25.4 & 1090 & 20.5 \\
\hline
\end{tabular}

(15.9\% [13.3-18.4]) than other educational levels and among those intermediate occupation level (14.9\% [10.4-19.4]).

The highest prevalence was observed among people within the highest income quintile $(16.2 \%$ [13.9-18.5]) compared to the lowest quintile $(6.9 \%[5.4-8.3])$. 
Table 2 Evolution of the prevalence of high cardiovascular risk prevalence by social determinants between 2005 and 2016

\begin{tabular}{|c|c|c|c|c|}
\hline \multirow[t]{2}{*}{ Study } & \multicolumn{2}{|c|}{ TAHINA-2005 } & \multicolumn{2}{|c|}{ THES-2016 } \\
\hline & $\mathrm{N}$ & High cardiovascular risk prevalence \%[Cl 95] & $\mathrm{N}$ & High cardiovascular risk prevalence $\%[\mathrm{Cl} 95]$ \\
\hline \multicolumn{5}{|l|}{ Characteristics } \\
\hline Gender & & $P=0.110$ & & $P=0.269$ \\
\hline Male & 3233 & $13.6[12.0-15.0]$ & 2610 & $21.1[19.2-22.9]$ \\
\hline Female & 4320 & $11.2[10.1-12.4]$ & 2839 & $19.6[17.9-21.3]$ \\
\hline Age-Groups (years) & & $p<10^{-3}$ & & $P<10^{-3}$ \\
\hline $35-44$ & 2992 & $7.4[6.2-8.7]$ & 1803 & $11.2[9.4-13.0]$ \\
\hline $45-54$ & 2469 & $14.1[12.3-15.9]$ & 1708 & $22.9[20.6-25.3]$ \\
\hline $55-64$ & 1319 & $19.1[16.5-21.7]$ & 1443 & $27.7[25.0-30.3]$ \\
\hline $65-70$ & 773 & $17.7[14.5-21.0]$ & 495 & $31.9[27.3-36.4]$ \\
\hline Area & & $P<10^{-3}$ & & $P<10^{-3}$ \\
\hline Urban & 4372 & $14.8[13.5-16.1]$ & 3606 & $22.8[21.2-24.4]$ \\
\hline Rural & 3181 & $7.3[6.3-8.3]$ & 1843 & $15.1[13.3-17.0]$ \\
\hline Region & & $P<10^{-3}$ & & $p=0.003$ \\
\hline District of Tunis & 925 & 19.2 [16.3-22.0] & 685 & 22.4 [19.1-25.7] \\
\hline North East & 1024 & $9.5[7.6-11.4]$ & 799 & 20.2 [17.3-23.0] \\
\hline North West & 1124 & $6.6[5.2-8.1]$ & 886 & 19.0 [16.3-21.7] \\
\hline Centre East & 1099 & 15.1 [12.9-17.2] & 836 & 22.1 [19.6-25.3] \\
\hline Centre West & 1176 & $7.9[6.3-9.4]$ & 763 & 16.2 [13.5-18.8] \\
\hline South East & 1070 & 8.8 [6.9-10.6] & 708 & 16.2 [13.4-19.0] \\
\hline South West & 1135 & $8.0[6.4-9.6]$ & 772 & 20.3 [17.4-23.3] \\
\hline Level of education & & $P=0.057$ & & $P=0.003$ \\
\hline Illiterate & 3258 & $10.7[9.4-11.9]$ & 1240 & 22.9 [20.2-25.6] \\
\hline Primary & 2588 & 12.3 [10.7-13.9] & 2117 & $21.1[19.1-23.1]$ \\
\hline Secondary & 1233 & 15.9 [13.3-18.4] & 1472 & 19.6 [17.3-22.0] \\
\hline University & 474 & $11.7[8.3-15.1]$ & 620 & 15.6 [12.1-19.0] \\
\hline Occupation & & $P=0.021$ & & $P=0.038$ \\
\hline Unemployed/retired & 3844 & 11.5 [10.2-12.8] & 2461 & 22.6 [20.7-24.5] \\
\hline Employee/worker & 2370 & 12.2 [10.6-13.9] & 2187 & 18.9 [17.0-20.8] \\
\hline Intermediate & 359 & 14.9 [10.4-19.4] & 317 & $18.9[13.7-24.1]$ \\
\hline Upper & 980 & 14.2 [11.5-16.9] & 484 & 18.6 [14.4-22.8] \\
\hline Quintile income & & $P<10^{-3}$ & & $P=0.017$ \\
\hline 1st quintile & 1510 & $6.9[5.4-8.3]$ & 1089 & 18.2 [15.6-20.8] \\
\hline 2nd quintile & 1510 & $9.0[7.2-10.7]$ & 1090 & $18.7[16.0-21.4]$ \\
\hline 3rd quintile & 1511 & $12.2[10.2-14.3]$ & 1090 & 21.9 [19.1-24.7] \\
\hline 4th quintile & 1511 & $14.9[12.6-17.1]$ & 1090 & 22.5 [19.6-25.4] \\
\hline 5th quintile & 1511 & 16.2 [13.9-18.5] & 1090 & 19.8 [17.0-22.6] \\
\hline Total & 7553 & $12.4[11.4-13.3]$ & 5449 & $20.3[19.1-21.6]$ \\
\hline
\end{tabular}

Cl 95 95\% Confidence Interval

p: $p$ value at $5 \%$ significance level

In 2016, the high cardiovascular risk prevalence increased to reach 20.3\% [19.1-21.6] among Tunisian adults aged between 35 and 70 years: $21.1 \%$ [19.2-22.9] among men and 19.6\% [17.9-21.3] among women. This prevalence increased gradually with age in 2016 where it was $11.2 \%$ [9.4-13.0] in those aged 35-44 years reaching $31.9 \%$ [27.3-36.4] in those aged 65-70 years of age.

In 2016, the highest prevalence of high cardiovascular risk was observed in the urban area $(22.8 \%$ [21.2-24.4]) and in the district of Tunis (22.4\% [19.1-25.7]). 
Additionally, the prevalence of high cardiovascular risk was particularly high among illiterate participants $(22.9 \%$ [20.2-25.6]), the unemployed and retired (22.6\% [20.7$24.5])$ and within the fourth income quintile $(22.5 \%$ [19.6-25.4]) (Table 2).

\section{Global sensitivity analysis in a logistic regression model method of high cardiovascular risk}

The global sensitivity analysis in a logistic regression model, reflecting the ranking of variables ordered by the level of importance and contribution of each o explaining the total variance of the high cardiovascular risk prevalence, showed that the most influential factors were the geographical area, the region of residence and the income contributing $30.7,21.4$ and $20.1 \%$ respectively in 2005.

In 2016, the education level occupied the first place $(36.1 \%)$, followed by the area $(26.2 \%)$ and the income (15.1\%). The occupation level represented $11.7 \%$ of the total variance (Table 3$)$.

\section{Wagstaff-type decomposition analysis of high cardiovascular risk prevalence}

Income-related inequality in high cardiovascular risk prevalence The concentration curves of income-related inequalities of high cardiovascular risk prevalence in 2005 and 2016 are presented in Fig. 5. The concentration curve lies under the diagonal line of equity, with the overall concentration index is estimated at 0.116 (95\% CI: 0.092 to 0.140 ) in 2005 and 0.085 (95\% CI 0.048 to 0.122 ) in 2016. High cardiovascular risk was mainly concentrated among those with the highest income in both observation periods (Fig. 1).

Decomposition analysis of high cardiovascular risk The Wagstaff decomposition analysis of high cardiovascular risk found that, in 2005, regional conditions had a

Table 3 Sensitivity indices and social determinants ranking of high cardiovascular risk

\begin{tabular}{|c|c|c|c|c|c|c|}
\hline \multirow{2}{*}{$\begin{array}{l}\text { Social } \\
\text { determinants }\end{array}$} & \multicolumn{3}{|l|}{2005} & \multicolumn{3}{|l|}{2016} \\
\hline & $S_{1}$ & $\mathrm{~S}_{\mathrm{i}}(\%)$ & Rank & $S_{1}$ & $\mathrm{~S}_{\mathrm{i}}(\%)$ & Rank \\
\hline Gender & 0.009 & 0.9 & 7 & 0.006 & 0.4 & 7 \\
\hline Age & 0.117 & 11.1 & 5 & 0.031 & 2.3 & 6 \\
\hline Area & 0.323 & 30.7 & 1 & 0.35 & 26.2 & 2 \\
\hline Region & 0.225 & 21.4 & 2 & 0.109 & 8.1 & 5 \\
\hline Education level & 0.045 & 4.3 & 6 & 0.483 & 36.1 & 1 \\
\hline Occupation & 0.122 & 11.6 & 4 & 0.157 & 11.7 & 4 \\
\hline Household income & 0.212 & 20.1 & 3 & 0.202 & 15.1 & 3 \\
\hline Total & 1.053 & 100.0 & & 1.338 & 100.0 & \\
\hline
\end{tabular}

S, Sensitivity indice principal role in explaining the income-related inequalities in high cardiovascular risk: The geographical area was in first place (34.6\%) followed by the region (21.8\%). The education level and occupation were ranked next explaining 13.8 and $13.2 \%$ respectively. Then, income explained $10.8 \%$. Lastly, age and gender contributed 4.8 and $1.0 \%$ to the observed inequalities respectively.

In 2016, the geographical area still occupied the first place and explained $40.3 \%$ of the adult social inequality in high cardiovascular risk followed by the income, education level and occupation with contributions of 19.2, 14.0 and $13.6 \%$ respectively. The age and the region represented 6.3 and $4.6 \%$ of the observed inequalities respectively. Gender only explained $2.1 \%$.

Based on the positive concentration indices in 2005 and 2016, men, people aged 45 to 54 years, residents in urban areas, residents in the North-East and CentralEast, those with secondary education, middle managers and those belonging to the highest income quintiles were mainly concentrated in the richer population. These groups contributed to the inequalities in the prevalence of high cardiovascular risk.

Furthermore, the social determinants included in the model accounted for 53 and $51 \%$ of the estimated inequality of high cardiovascular risk in Tunisia respectively in 2005 and 2016, based on the residual, reflecting the unexplained part of the inequality in terms of prevalence of high cardiovascular risk (Table 4).

\section{Discussion}

The study revealed a high evolution of cardiovascular risk factors among Tunisian adults during the last decade with substantial pro-rich income-related inequalities. Similar upward trends have been previously been shown [30,31] particularly in low and middleincome countries [32, 33].

We have used the two most common methods to measure and explain health inequalities, the global sensitivity analysis of logistic regression model and the Wagstaff-type decomposition analysis using the cardiovascular risk factors in the last decade as outcomes in Tunisia. To the best of our knowledge, this is the first study comparing these two methods mathematically and epidemiologically in Tunisia and the Maghreb region.

This study highlights that the results provided by the GSA and Wagstaff decomposition analysis methods show that higher risk for cardiovascular diseases is concentrated among those with higher socio-economic status in 2005. Similar results were observed in 2016. Moreover, both methods show similar factors explain the inequalities (income, educational level and regional conditions (area and region)) but with different rankings of importance. 


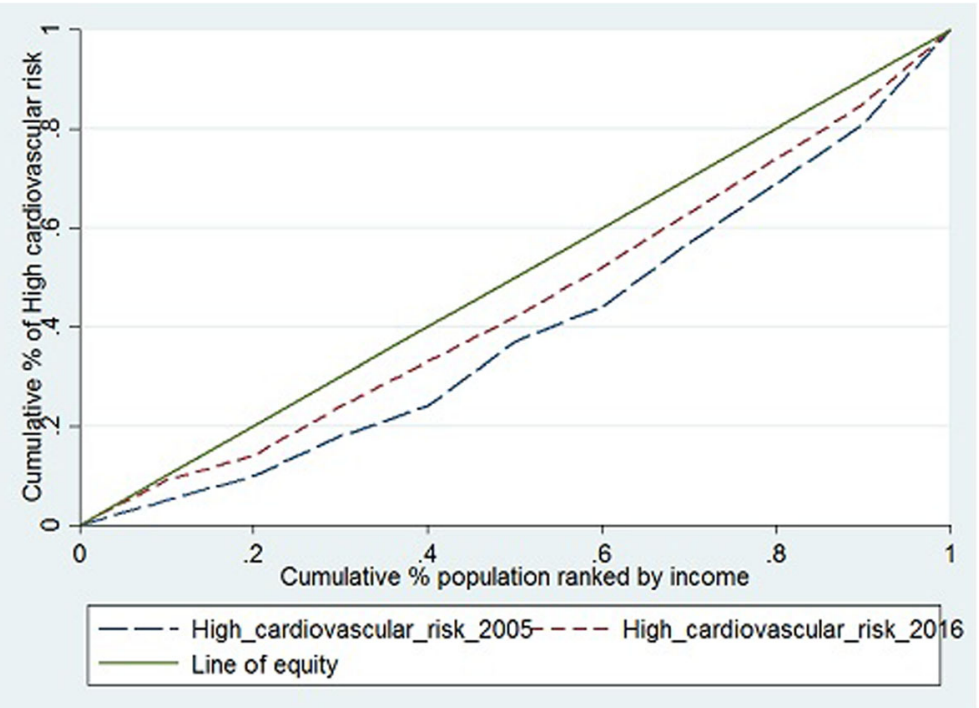

Fig. 1 The concentration curve of income-related inequality in high cardiovascular risk among Tunisian adults in 2005 and 2016

An interesting result from this analysis is that those with high socio-economic status have a higher risk for cardiovascular diseases and diabetes than those from lower socio-economic groups in both 2005 and 2016, except for hypertension. Hypertension was the most prevalent disease in the lowest socio-economic groups in 2016 and the use of tobacco in 2016, was most common in those with income in the mid-range. The findings of the present study are generally in line with another $\mathrm{Tu}$ nisian study which showed that those with high living standards had a three times higher risk of developing a cardiovascular event in 10 years than those with low living standards [34].

Result are also consistent with the descriptive study conducted in 2011 in Morocco that showed that cardiovascular risk increased proportionally with household income [35].

In contrast to our results, other studies from low and middle-income countries have shown that cardiovascular risk factors are often higher in groups with low socioeconomic status than in those with high socioeconomic status [36-38]. These studies have suggested that observed social gradient depends on the economic and social context of the country.

It is known that income-related inequalities in cardiovascular risk factors and diabetes exist in all countries and are considered unacceptable [39-44]. The challenge facing policymakers is, to ensure that strategies for reducing inequalities must be targeted and justified by rigorous research.

A study in Swedish middle-aged women and men showed that the magnitude of income-related inequalities in CVRFs and their determinants differed between the risk factors and gender. Income was the dominant factor for BMI, abdominal obesity, triglycerides, glucose regulation and LDL-cholesterol, explaining between 30 and $49 \%$ of the inequality, whereas education was more important for HDL-cholesterol and total-cholesterol (explaining 24.3 and $41.0 \%$ respectively), and occupation was more important for blood pressure (explaining 47.3\%) [45].

We found similar results in our study. Income was the major factor for obesity, hypertension hypercholesterolemia and diabetes in Tunisia in 2016, and education was more important for tobacco use.

A key priority message of this study is that the income-related inequalities of cardiovascular risk factors and diabetes are explained by regional disparities, education level and income.

Thus, in Tunisia, promoting equity through universal coverage and improving access to quality care, are two fundamental elements to help remedy the situation and interventions should specially be targeted to high risk groups [46].. It is also important to improve the governance of the system and to make the multisectoral approach a reality for a more effective response to major health problems, such as cardiovascular disease and diabetes.

In term of methodology, several studies in the field have used a simple logistic regression for the study of association between the outcome and determinants Where the results are interpreted in terms of odds ratio (OR) $[9,10,47]$.

To overcome the limitations of the single logistic regression some studies develop a global sensitivity analysis to assess the relative importance of input 
Table 4 Decomposition of the concentration index of high cardiovascular risk prevalence among Tunisian adults in2005 and 2016

\begin{tabular}{|c|c|c|c|c|c|c|c|c|c|c|c|c|}
\hline & \multicolumn{6}{|l|}{2005} & \multicolumn{6}{|l|}{2016} \\
\hline & Coef & Elast & $\mathrm{Cl}$ & Cont to $\mathrm{C}$ & $\%$ cont & $\%$ Adj & Coef & Elast & $\mathrm{Cl}$ & Cont to $\mathrm{C}$ & $\%$ cont & $\%$ Adj \\
\hline Gender & & & & & & 1.0 & & & & & & 2.1 \\
\hline \multicolumn{13}{|l|}{ Female (Ref) } \\
\hline Male & 0.004 & 0.015 & 0.129 & 0.002 & 1.7 & 1.0 & 0.021 & 0.048 & 0.070 & 0.003 & 3.9 & 2.1 \\
\hline Age & & & & & & 4.8 & & & & & & 6.3 \\
\hline 35-44 years (Ref) & & & & & & 0.0 & & & & & & 0.0 \\
\hline 45-54 years & 0.071 & 0.221 & 0.043 & 0.010 & 8.2 & 4.8 & 0.133 & 0.203 & 0.050 & 0.010 & 12.0 & 6.3 \\
\hline $55-64$ years & 0.150 & 0.249 & -0.032 & -0.008 & -6.9 & 0.0 & 0.184 & 0.238 & -0.081 & -0.019 & -22.7 & 0.0 \\
\hline $65-70$ years & 0.162 & 0.158 & -0.157 & -0.025 & -21.3 & 0.0 & 0.238 & 0.106 & -0.179 & -0.019 & -22.2 & 0.0 \\
\hline Area & & & & & & 34.6 & & & & & & 40.3 \\
\hline Rural (ref) & & & & & & 0.0 & & & & & & 0.0 \\
\hline Urbain & 0.032 & 0.174 & 0.398 & 0.069 & 59.5 & 34.6 & -0.079 & -0.131 & -0.497 & 0.065 & 76.4 & 40.3 \\
\hline Region & & & & & & 21.8 & & & & & & 4.6 \\
\hline \multicolumn{2}{|c|}{ District of Tunis (Ref) } & & & & & 0.0 & & & & & & 0.0 \\
\hline North_east & -0.049 & -0.063 & 0.014 & -0.001 & -0.7 & 0.0 & 0.006 & 0.004 & 0.043 & 0.000 & 0.2 & 0.1 \\
\hline North_west & -0.060 & -0.085 & -0.232 & 0.020 & 17.0 & 9.9 & 0.003 & 0.002 & -0.275 & -0.001 & -0.7 & 0.0 \\
\hline Central_east & -0.016 & -0.022 & 0.244 & -0.005 & -4.6 & 0.0 & 0.022 & 0.016 & 0.252 & 0.004 & 4.8 & 2.5 \\
\hline Central_west & -0.046 & -0.068 & -0.262 & 0.018 & 15.2 & 8.9 & -0.013 & -0.009 & -0.265 & 0.002 & 2.7 & 1.4 \\
\hline South_east & -0.052 & -0.071 & 0.035 & -0.002 & -2.1 & 0.0 & -0.053 & -0.034 & -0.024 & 0.001 & 0.9 & 0.5 \\
\hline South_west & -0.054 & -0.078 & -0.078 & 0.006 & 5.2 & 3.0 & -0.001 & -0.001 & 0.060 & 0.000 & 0.0 & 0.0 \\
\hline \multicolumn{2}{|l|}{ Education Level } & & & & & 13.8 & & & & & & 14.0 \\
\hline Illiterate & 0.015 & 0.060 & -0.412 & -0.025 & -21.3 & 0.0 & 0.082 & 0.091 & -0.509 & -0.047 & -54.6 & 0.0 \\
\hline Primary & 0.038 & 0.125 & -0.008 & -0.001 & -0.9 & 0.0 & 0.071 & 0.134 & -0.220 & -0.029 & -34.4 & 0.0 \\
\hline Secondary & 0.042 & 0.066 & 0.421 & 0.028 & 23.7 & 13.8 & 0.052 & 0.068 & 0.334 & 0.023 & 26.6 & 14.0 \\
\hline University (ref) & & & & & & 0.0 & & & & & & 0.0 \\
\hline \multicolumn{2}{|l|}{ Occupation } & & & & & 13.2 & & & & & & 13.6 \\
\hline Unemployed & -0.022 & -0.106 & -0.216 & 0.023 & 19.7 & 11.5 & -0.021 & -0.045 & -0.202 & 0.009 & 10.7 & 5.7 \\
\hline Workers & -0.028 & -0.084 & -0.041 & 0.003 & 3.0 & 1.7 & -0.039 & -0.077 & -0.167 & 0.013 & 15.0 & 7.9 \\
\hline Medium & -0.014 & -0.006 & 0.683 & -0.004 & -3.7 & 0.0 & -0.016 & -0.005 & 0.506 & -0.002 & -2.7 & 0.0 \\
\hline High (Ref) & & & & & & 0.0 & & & & & & 0.0 \\
\hline \multicolumn{2}{|l|}{ Household income } & & & & & 10.8 & & & & & & 19.2 \\
\hline Lowest quintile & -0.035 & -0.068 & -0.993 & -0.067 & -57.7 & 0.0 & -0.022 & -0.022 & -0.999 & 0.022 & 25.4 & 13.4 \\
\hline 2 & -0.021 & -0.041 & -0.507 & 0.021 & 17.8 & 10.3 & 0.004 & 0.004 & -0.498 & -0.002 & -2.1 & 0.0 \\
\hline 3 & -0.006 & -0.011 & 0.001 & 0.000 & 0.0 & 0.0 & 0.024 & 0.023 & 0.005 & 0.000 & 0.1 & 0.1 \\
\hline 4 & 0.001 & 0.002 & 0.498 & 0.001 & 0.7 & 0.4 & 0.019 & 0.019 & 0.498 & 0.009 & 10.9 & 5.7 \\
\hline \multicolumn{2}{|c|}{ Highest quintile (ref) } & & & 0.000 & & 0.0 & & & & & & 0.0 \\
\hline C (conindu) & 0.116 & & & & & & 0.085 & & & & & \\
\hline Residual & 0.055 & & & & & & 0.042 & & & & & \\
\hline
\end{tabular}

${ }^{a}$ Coeff coefficient, Elas elasticity, C concentration index, Cont. to C contribution to concentration index, \% percentage contribution, Adj \% Adjusted percentage

parameters in the system model and the relative importance of variables allowing analysis of the robustness of the logistic model $[28,48]$.

Unfortunately, this approach also has some limitations as it based on the sampling of the distribution function and is not intended to identify the cause of the input variability. It only indicates the type and extent of impact on the model output. Therefore, it cannot be used to determine the source(s) of variance.

Other advanced and recent methods have also been developed to study income-related inequalities such as Wagstaff's decomposition analysis [29]. This approach 
should help to overcome the limitations of the previous approach. This method demonstrates that the health concentration index can be decomposed into the contributions of individual factors to income-related health inequality, in which each contribution is the product of the sensitivity of heath with respect to that factor (the elasticity) and the degree of income-related inequality in that factor (the respective concentration index).

These two methods differ on the mathematical and statistical level; however, they can be complementary in application to public health and help address the expectations of decision-makers.

The GSA and the decomposition gave similar results, however, the decomposition requires much more information to be performed and is mathematically a more complex method.

Therefore, in settings where: a) information is not routinely collected or data do not match the standard requirements to run a decomposition or b) the statistical skills are not in place, then a GSA could be carried out similar results are shown.

\section{Conclusions}

Our study revealed considerable inequalities in cardiovascular risk factors and diabetes in Tunisia in 2005 and 2016, before and after the revolution. The results suggest that most of this inequality can be attributed to socioeconomic factors, regional conditions (region and area of residence) and demographics.

The results, therefore, suggest that income and educational level inequalities as well as regional conditions (area and region) represent the main factors responsible for the income-related inequalities in cardiovascular risk factors and diabetes in Tunisia during the last decade.

The results to explain the income-related inequalities of cardiovascular disease and diabetes in Tunisia over time are consistent across the two methods used, the global sensitivity analysis of logistic regression and the decomposition of the concentration index. The findings contribute to gaps in the literature concerning the analysis of social determinants in mathematical and epidemiological terms.

This study argues that, although, the two methods used are mathematically different in nature, their results are complementary and can provide valuable explanations to the observed social inequities of cardiovascular risk factors and diabetes.

Thus, these findings suggest that addressing the root cause of inequality is essential for promoting cardiovascular risk factors and diabetes equity in Tunisia.

The information provided by the analysis might be helpful to identify potential targets for health interventions in order to reduce these income-related inequalities in Tunisia and the methods can be applied to other health problems and populations.

\section{Abbreviations}

ADA: American Diabetes Association; BMl: Body Mass Index; C: Concentration index; CC: Concentration Curve; CVDs: Cardiovascular Diseases; DBP: Diastolic Blood Pressure; FPG: Fasting Plasma Glucose; GSA: Global Sensitivity Analysis; HbA1C: Hemoglobin A1C; OR: Odds Ratio; SBP: Systolic Blood Pressure; s: Sensitivity index; TAHINA-2005: Epidemiological Transition and Health Impact in North Africa Survey-2005; THES-2016: Tunisian Health Examination Survey-2016; WHO: World Health Organization

\section{Acknowledgements}

We thank all the Tunisian National Health Institute team for the collaboration in both surveys (TAHINA and THES). Appreciation should go to all the dedicated field workers and those who helped facilitate the field works in both surveys. We thank also the WHO team to collaborate in the THES survey.

Our knowledge to the Research Laboratory in Epidemiology and Prevention of Cardiovascular Diseases, the National Office of Family and Population and Tunisian Diabetes Association for their collaboration in the THES survey.

\section{Authors' contributions}

OS, MOF, SC, DM and HBR conceived the idea of the study. OS and NZ analysed the data with support from PM.

OS, NZ, DM and MOF wrote the first draft of the paper and OS, HBR, MOF,

SC, KB and PM finalized the manuscript. All authors contributed to the analysis, intellectual content, critical revisions to the drafts of the paper and approved the final version.

\section{Funding}

The TAHINA-2005 survey was funded by the European Commission (ICA3-CT2002-1001). The THES Survey was funded by the Tunisian National Health Institute, the Tunisian Ministry of Health and the World Health Organization (WHO) in collaboration with the Research Laboratory in Epidemiology and Prevention of Cardiovascular Diseases, the National Office of Family and Population and Tunisian Diabetes Association.

\section{Availability of data and materials}

For TAHINA-2005 survey, the datasets used and analyzed during the current study are available from the corresponding author on reasonable request. For THES-2016 survey, The Tunisian Ministry of Health/National Institute of Health and World Health Organization will publish the datasets online.

\section{Ethics approval and consent to participate}

The main ethical considerations applicable to all forms of medical research stemming from the declaration of Helsinki of the World Medical Association have been respected for both surveys (TAHINA-2005 and THES-2016). For THES-2016 survey, the protocol of the study was approved by the Tunisian Ministry of Health and the World Health Organization. The protocol was also approved by the Tunisian National Council of Statistics (Visa $n^{\circ}$ 09-2015 of 10 November 2015) and by the National Body for the Protection of Personal Data (Authorization to process health data $N^{\circ} 185-01 / 16$ from 06 May 2016).

For TAHINA-2005 survey, the protocol of the study was approved by Tunisian Ministry High Education and Research, Ministry of Health and the Tunisian National Council of Statistics.

For both surveys, at the beginning of the study, each randomly selected participant was appropriately informed about the objectives, methods, funding, institutional affiliation, expected benefits and data collection modalities. Before the inclusion of each participant, verbal consent was obtained from him or his parents.

\section{Consent for publication}

For both surveys used in this study, before the inclusion of each participant, verbal consent was obtained for participation and publication.

\section{Competing interests}

The authors have declare that they have no competing interests.

\section{Author details}

${ }^{1}$ Cardiovascular Epidemiology and Prevention Research Laboratory -Faculty of medicine of Tunis, University Tunis El Manar, Tunis, Tunisia. ${ }^{2}$ National Institute of Health, Tunis, Tunisia. ${ }^{3}$ Population and Health Sciences, Royal 
College of Surgeons in Ireland, Dublin, Ireland. ${ }^{4}$ Department of Epidemiology and Global Health, Umeå University, Umeå, Sweden. ${ }^{5}$ National Institute of Statistics and Data Analysis Tunis, Tunis, Tunisia. ${ }^{6}$ Department of Public Health and Policy, University of Liverpool, Liverpool, UK.

\section{Received: 4 March 2019 Accepted: 3 September 2019}

\section{Published online: 15 November 2019}

\section{References}

1. Report of the International Conference on Primary Health Care Alma-Ata, USSR, 6-12 September 1978. https://www.unicef.org/about/history/files/ Alma_Ata_conference_1978_report.pdf

2. Closing the gap in a generation. health equity through action on the social determinants of health. Final Report of the Commission on Social Determinants of Health. Geneva: World Health Organization; 2008. http:// apps.who.int/iris/bitstream/10665/43943/1/9789241563703_eng.pdf

3. Saidi $O$, et al. La santé des Tunisiens : Résultats de l'enquête "Tunisian Health Examination Survey-2016". Février: Publication de I'Institut National de la Santé; 2019. http://www.santetunisie.rns.tn/fr/toutes-les-actualites/912rapport-de-1\%E2\%80\%99enqu\%C3\%AAte-national-thes-2016

4. Ben $\mathrm{RH}$. Enquête Nationale Santé Transition épidémiologique et système de santé-Tunisie. Projet TAHINA; 2005.

5. Moody A, Cowley G, Fat LN, Mindell JS. Social inequalities in prevalence of diagnosed and undiagnosed diabetes and impaired glucose regulation in participants in the Health Surveys for England series. BMJ Open. 2016;6: e010155. https://doi.org/10.1136/bmjopen-2015-010155.

6. Zaman J, Brunner E. Social inequalities and cardiovascular disease in South Asians. Heart. 2008:94(4):406-7.

7. Boutayeb, Helmert. Social inequalities, regional disparities and health inequity in North African countries. Int J Equity Health. 2011;10:23 http:// www.equityhealthj.com/content/10/1/23.

8. Romdhane HB, Grenier FR. Social determinants of health in Tunisia: the case-analysis of Ariana. Int J Equity Health. 2009;8:9. https://doi.org/10.1186/ 1475-9276-8-9 Published online 2009 Apr 3.

9. Romdhane B, et al. Prevalence of diabetes in Northern African countries: the case of Tunisia. BMC Public Health. 2014;14:86 http://www.biomedcentral. com/1471-2458/14/86

10. Romdhane $B$, et al. Hypertension among Tunisian adults: results of the TAHINA project. Hypertens Res. 2012;35:341-7.

11. Hussain JN. Sensitivity analysis to select the Most influential risk factors in a logistic regression model: International Journal of Quality, Statistics, and Reliability Volume; 2008. https://www.hindawi.com/journals/jqre/2008/471607/.

12. Mosquera PA, San Sebastian M, Waenerlund AK, Ivarsson A, Weinehall L, Gustafsson PE. Income-related inequalities in cardiovascular disease from mid-life to old age in a northern Swedish cohort: a decomposition analysis. Soc Sci Med. 2016. https://www.ncbi.nlm.nih.gov/pubmed/26717560.

13. Quarells RC, Liu J, Davis SK. Social determinants of cardiovascular disease risk factor presence among rural and urban black and white men. J Mens health. 2012;9(2):120-6. https://doi.org/10.1016/j.jomh.2012.03.004.

14. Lang T, Lepage B, Schieber AC, Lamy S, Kelly-Irving M. Social determinants of cardiovascular diseases. Public Health Rev. 2012;33:601-22.

15. National Statistics Institute of Tunisia: Results of the 2004 census. http:// www.ins.tn/fr/publication/recensement-g\%C3\%A9n\%C3\%A9ral-de-lapopulation-et-de-Ihabitat-de-2004-premiers-r\%C3\%A9sultats-volume-1 (Accessed 27 Feb 2018).

16. National Statistics Institute of Tunisia: Results of the 2014 census. http:// census.ins.tn/fr/resultats\#horizontalTab4 (Accessed 27 Feb 2018).

17. Institut National de la statistique. Caractéristiques d'éducation de la population, vol. 4: Recensement Général de la Population et de l'Habitat; 2014. http://census.ins.tn/sites/default/files/vol4.pdf. Janvier 2017

18. Bureau international du travail. Structure de la Classification internationale type des professions, Genève, 2008 (CITP-08).

19. Organisation Mondiale de la Santé. Hypertension artérielle : un problème de santé publique. http://www.who.int/features/qa/82/fr/.

20. WHO Consultation Report. Definition, Diagnosis and Classification of Diabetes Mellitus and its Complications. In: Part 1: Diagnosis and Classification of Diabetes Mellitus. Geneva: Department of Non communicable Disease Surveillance, WHO; 1999. http:/whalibdoc.who.int/hq/1999/who_ncd_ncs_99.2.pdf.

21. American Diabetes Association. Standards of medical care in diabetes - 2016. January 2016 Volume 39, Supplement 1. The journal of clinical and applied research and education January 2016 Volume 39, Supplement 1.
22. American Diabetes Association. Standards of medical care in diabetes, 2009. Diabetes care, volume 35, supplement 1, January 2012

23. Organisation Mondiale de la Santé. Cholestérol sérique total élevé, couverture pharmaceutique et contrôle thérapeutique: une analyse des données nationales d'enquête sur les examens de santé émanant de huit pays.http://www.who.int/bulletin/volumes/89/2/10-079947-ab/fr/. (Accessed 05 Mar 2018)

24. World Health Organization. Obesity: preventing and managing the global epidemic (WHO, 2000)

25. Saltelli A. Global sensitivity analysis: an introduction. In: Hanson KM, Hemez FM, editors. Sensitivity Analysis of Model Output. LosAlamos: Los Alamos National Laboratory; 2005. p. 27-43.

26. Lu R, Wang D, Wang M, Rempala G. Estimation of Sobol's Sensitivity Indices under Generalized Linear Models. Commun Stat Theory Methods. 2017. https://www.ncbi.n/m.nih.gov/pmc/articles/PMC6141050/.

27. Ancel P-Y. Méthodes avancées en épidémiologie: La régression logistique en épidémiologie; 2012.

28. Scott A. Czepiel. Maximum Likelihood Estimation of Logistic Regression Models: Theory and Implementation. https://czep.net/stat/mlelr.pdf. (Accessed 05 Mar 2018).

29. O'Donnell O, van Doorslaer E, Wagstaff A. Magnus Linde low Analyzing Health Equity Using Household Survey Data. In: A Guide to Techniques and Their Implementation: The International Bank for Reconstruction and Development. The World Bank; 2008. http://siteresources.worldbank.org/ INTPAH/Resources/Publications/459843-1195594469249/HealthEquityFINAL. pdf.

30. Kaan Sozmen, Belgin Unal, Olfa Saidi et al. Cardiovascular risk factor trends in the eastern Mediterranean region: evidence from four countries is alarming. Int J Public Health. 2017. https://www.ncbi.nlm.nih.gov/pubmed/25280526.

31. Saidi O, O'Flaherty M, Mansour NB, Aissi W, Lassoued O, Capewell S, Critchley JA, Malouche D, Romdhane HB. EC FP7 funded MEDCHAMPS project.. Forecasting Tunisian type 2 diabetes prevalence to 2027: validation of a simple model. BMC Public Health. 2015;15:104. https://doi.org/10.1186/ s12889-015-1416-z

32. Sarki AM, Nduka CU, Stranges S, Kandala N-B, Uthman OA. Prevalence of Hypertension in Low- and Middle-Income Countries A Systematic Review and Meta-Analysis. Medicine. 2015;94(50):e1959.

33. Turk-Adawi K, Sarrafzadegan N, Fadhil I, Taubert K, Sadeghi M, Wenger NK, Tan NS, Grace SL. Cardiovascular disease in the Eastern Mediterranean region: epidemiology and risk factor burden. Nat Rev Cardiol. 2017;15:106-19.

34. Saidi $\mathrm{O}$, Malouche $\mathrm{D}$, O'Flaherty $\mathrm{M}$, et al. Assessment of cardiovascular risk in Tunisia: applying the Framingham risk score to national survey data. BMJ Open. 2016;6:e00195. https://doi.org/10.1136/bmjopen-2015.

35. Boutahiri N. Estimation du risque cardiovasculaire chez le personnel de I'hôpital régional Mohammed V de Meknes (à propos de 512cas). 2011. https://scolarite.fmpusmba.ac.ma/cdim/mediatheque/e theses/32-11.pdf.

36. Sommer I, Griebler U, Mahlknecht P, Thaler K, Bouskill K, Gartlehner G, Mendis S. Socioeconomic inequalities in non-communicable diseases and their risk factors: an overview of systematic reviews. BMC Public Health. 2015;15:914. https://doi.org/10.1186/s12889-015-2227-y.

37. Niessen LW, Mohan D, Akuoku JK, Mirelman AJ, Ahmed S, Koehlmoos TP, Trujillo A, Khan J, Peters DH. Tackling socioeconomic inequalities and non-communicable diseases in low-income and middle-income countries under the Sustainable Development agenda. Lancet. 2018. https:/doi.org/10.1016/S0140-6736(18)30482-3.

38. Hosseinpoor AR, Bergen N, Kunst A, Harper S, Guthold R, Rekve D, d'Espaignet ET, Naidoo N, Chatterij S. Socioeconomic inequalities in risk factors for non-communicable diseases in low-income and middle-income countries: results from the world health survey. BMC Public Health. 2012;12: 912. https://doi.org/10.1186/1471-2458-12-912.

39. Hosseinpoor AR, Parker LA, Tursan d'Espaignet E, Chatterji S. Socioeconomic inequality in smoking in low-income and middle-income countries: results from the world health survey. PLoS One. 2012;7(8):e42843. https://doi.org/ 10.1371/journal.pone.0042843 Epub 2012 Aug 29.

40. Dégano I, Marrugat J, Grau M, Salvador-González B, Ramos R, Zamora A, Martí R, Elosua R. The association between education and cardiovascular disease incidence is mediated by hypertension, diabetes, and body mass index. Sci Rep. 2017:7:12370. https://doi.org/10.1038/s41598-017-10775-3.

41. Di Cesare M, Khang YH, Asaria P, Blakely T, Cowan MJ, Farzadfar F, Guerrero R, Ikeda N, Kyobutungi C, Msyamboza KP, Oum S, Lynch JW, Marmot MG, Ezzati M, Lancet NCD Action Group. Inequalities in non-communicable 
diseases and effective responses. Lancet. 2013;381(9866):585-97. https://doi. org/10.1016/S0140-6736(12)61851-0 Epub 2013 Feb 12.

42. Adjaye-Gbewonyo K, Kawachi I, Subramanian SV, Avendano M. Income inequality and cardiovascular disease risk factors in a highly unequal country: a fixed-effects analysis from South Africa. Int J Equity Health. 2018; 17(1):31. https://doi.org/10.1186/s12939-018-0741-0.

43. Review M. Fair society, healthy lives: strategic review of health inequalities in England post 2010: UCL Institute of Health Equity; 2010.

44. Kypridemos C, Allen K, Hickey GL, Guzman-Castillo M, Bandosz P, Buchan I, Capewell S, O'Flaherty M. Cardiovascular screening to reduce the burden from cardiovascular disease: micro simulation study to quantify policy options. BMJ. 2016;353:i2793. https://doi.org/10.1136/bmj.i2793.

45. Mosquera PA, et al. Decomposition of gendered income-related inequalities in multiple biological cardiovascular risk factors in a middle-aged population. Int J Equity Health. 2018;17:102.

46. Belhadj $\mathrm{H}$ et al. Le droit à la santé en Tunisie. 2016. http://ftdes.net/ rapports/ATDDS.pdf

47. Lang S-J, Abel GA, Mant J, et al. Impact of socioeconomic deprivation on screening for cardiovascular disease risk in a primary prevention population: a cross-sectional study. BMJ Open. 2016;6.

48. Thabane, et al. A tutorial on sensitivity analyses in clinical trials: the what, why, when and how. BMC Med Res Methodol. 2013;13:92 http://www. biomedcentral.com/1471-2288/13/92.

\section{Publisher's Note}

Springer Nature remains neutral with regard to jurisdictional claims in published maps and institutional affiliations.

Ready to submit your research? Choose BMC and benefit from:

- fast, convenient online submission

- thorough peer review by experienced researchers in your field

- rapid publication on acceptance

- support for research data, including large and complex data types

- gold Open Access which fosters wider collaboration and increased citations

- maximum visibility for your research: over $100 \mathrm{M}$ website views per year

At BMC, research is always in progress.

Learn more biomedcentral.com/submissions 